\title{
O declínio dos jornais
}

oucos setores sofreram tanto com o avanço das tecnolo-
gias de informação como o de jornais. Por longo tempo,
eles foram o meio privilegiado pelo qual as pessoas tinham acesso às informações. Agora, com a concorrência de novas mídias, principalmente a Internet, os jornais estão sendo obrigados a se reinventar para sobreviver. 0 artigo analisa de que forma a crise atingiu os principais jornais do mundo e como al guns a têm contornado.

por Rafael Alcadipani FGVEAESP eManchester Business School

Os jornais foram o grande palco da história do último século. N enhum evento que despertasse atenção foi deixado de lado. Eles cumpriram, e ainda cumprem, papel fundamental no estabelecimento e consolidação de democracias ao possibilitar que as pessoas fiquem conectadas ao mundo que existe a sua volta.
Mesmo com a popularização do uso de rádios e TVs, jornais de circulação nacional mantiveram sua destacada importância e diários locais se consolidaram como espaços em que assuntos da comunidade são debatidos e seu mercado se manifesta. Diários sempre foram muito importantes para os negócios. Foram também, por muito 
tempo, o meio pelo qual celebridades encontravam seu público e, ao mostrar seu jeito de se vestir, os lugares que freqüentavam, ditaram moda.

Antes da Internet, era onde os investidores podiam consultar o comportamento de suas ações nos pregões das bolsas de valores. Representaram um espaço em que aquel es que procuram emprego e empresas, vendedores e compradores, analistas econômicos e as pessoas em geral, imobiliárias e o sonho da casa nova, encontravam uns aos outros. Os classificados de domingo eram verdadeiras lojas de departamento. Esse é o cenário desde a criação do que conhecemos como o jornal moderno ao redor de 1600 na Alemanha. tração e depreciação de equipamentose $21 \%$ para os demais custos. Em termos de receitas, o quadro típico é bem mais simples: $70 \%$ provenientes de propaganda e classificados, enquanto $30 \%$ vêm da venda do produto.

A criação da rotativa com partes móveis por Gutenberg em 1440 já lançara as bases para que jornais pudessem ser impressos em grande quantidade e a um custo que viabilizasse o negócio. Até muito recentemente, tais máquinas evoluíram seguindo o modelo idealizado há séculos como demonstra a impressão off-set. A tônica tem sido o desenvolvimento de máquinas e equipamentos que permitam a impressão da maior quantidade da mesma edição de um dado jornal ao menor custo possível.

\section{Notícias e informações de todos os tipos,} de qualquer lugar do mundo, podem ser adquiridas de forma gratuita nas

\section{diversas páginas da Internet com uma}

\section{grande vantagem: não requerem rotativas,} bobinas de papel, eletricidade e complexas redes de distribuição para existir.

Natureza do produto. Jornais estão entre os produtos mais perecíveis do mercado: sua vida útil nas prateleiras é de, no máximo, 12 horas. Uma das maiores máximas dessa indústria é "ninguém paga pelas notícias de ontem". Por isso, para prosperar economicamente, o produto demanda a fidel idade absoluta de seus leitores, que precisam comprá-lo diariamente nas bancas ou se comprometer com o produto por relativo longo prazo ao comprar uma assinatura.

Tipicamente, um jornal que ocupa uma posição monopolista em um mercado médio tem uma margem de lucro ao redor de $30 \%$ nos Estados Unidos. Os custos de um jornal com circulação ao redor de 100 mil cópias diárias seriam provavelmente divididos da seguinte forma: $12 \%$ para cobrir despesas editoriais, 10\% para propaganda, $11 \%$ para distribuição, 21\% para produção, 25\% para adminis-
I mpactos tecnológi cos. $\mathrm{N}$ a realidade, talvez poucas indústrias tenham sentido tanto os desenvolvimentos tecnológicos. Não faz muito tempo, as placas que são colocadas nos cilindros das rotativas e quegeram a impressão de jornal eram feitas manualmente. Palavra por palavra, letra por letra, eram feitas de metal e formavam a página que seria impressa. Hoje, sofisticadas máquinas laser comandadas por computadores de última geração fazem o serviço. Já existem protótipos de grandes rotativas que não usam placas e possibilitam a alteração do conteúdo enquanto o jornal é impresso, algo totalmente impensável há 10 anos.

No passado, as rotativas dos jornais tinham de estar muito próximas das redações, pois toda a informação para impressão era repassada por uma imensa quantidade de papéis e formulários. Era possível sentir o prédio tremer quando o jornal começava a ser "rodado". Atualmente, a digitalização permite que um jornal editado em São Paulo seja impresso em Tóquio. Isso sem falar na revolução que essas empresas testemunharam na transição da máquina de escrever para o computador, da fotografia com o uso de filme, que demandava laboratórios de revelação e toda uma parafernália de equipamentos e produtos químicos, para as fotos digitais que são repassadas para os editores quase que instantaneamente. 
Em geral, até muito recentemente as mudanças tecnológicas representaram a possibilidade tanto da redução de custos de pessoal quanto de demais equipamentos e meios de produção nessas organizações. Por exemplo, as rotativas de última geração utilizam muito menos água, tinta e energia elétrica, geram menos desperdício de papel e precisam da metade dos operadores do que aquelas concebidas há 25 anos. Isso sem falar nas economias representadas pelas mudanças nas tecnologias de produção de placas, fotografia etc.

Momento de crise. Apesar de todos os benefícios e economias gerados pelas novas tecnologias, as empresas de jornal enfrentam hoje a maior crise de sua história. Títulos como Le Monde, The Guardian e The New York Times estão enfrentando declínios significativos em sua circulação diária. 0 The Times, mais antigo jornal do mundo, mudou de formato para tentar reverter essa tendência sem muito sucesso.

No Brasil, a Folha deS. Paulo, jornal de maior circulação nacional, em 2001 tinha uma circulação média diária de cerca de 400 mil exemplares. Em 2005, o número caiu para pouco mais de 300 mil. Até mesmo os tablóides ingleses, conhecidos por serem campeões de vendas, perdem leito- res drasticamente. M esmo com uma respeitável circulação diária superior a 3 milhões de cópias, o The Sun perdeu quase $2 \%$ de seu mercado entre outubro de 2004 e outubro de 2005, valor típico para os últimos 8 anos.

Os jornais não estão perdendo leitores para outros jornais seus concorrentes, mas sim para outras mídias. Nos Estados Unidos, em 1964 quase 81\% dos adultos liam um jornal diariamente. Em 2004, esse percentual caiu para 52,8\%. Na França, entre 1972 até 2001, as vendas do produto caíram em $40 \%$. No Reino Unido, entre 1999 e 2002, os jornais perderam cerca de 5 miIhões de leitores. Nos países desenvolvidos, o mercado está constantemente em declínio desde o final dos anos de 1970 . No Brasil, ao redor de $39 \%$ das pessoas são leitoras de jornal.

Entendendo a crise. Não faltam razões para a crise: em um mundo superacelerado o tempo é recurso escasso. Como conseqüência, as pessoas dedicam menos tempo à aquisição de informações. Pesquisas no Reino Unido mostram que na década de 1970 as pessoas dedicavam, em média, cerca de 1 hora diária somente à leitura de jornais, enquanto hoje gastam menos de 30 minutos na leitura de notícias nos mais diversos meios.

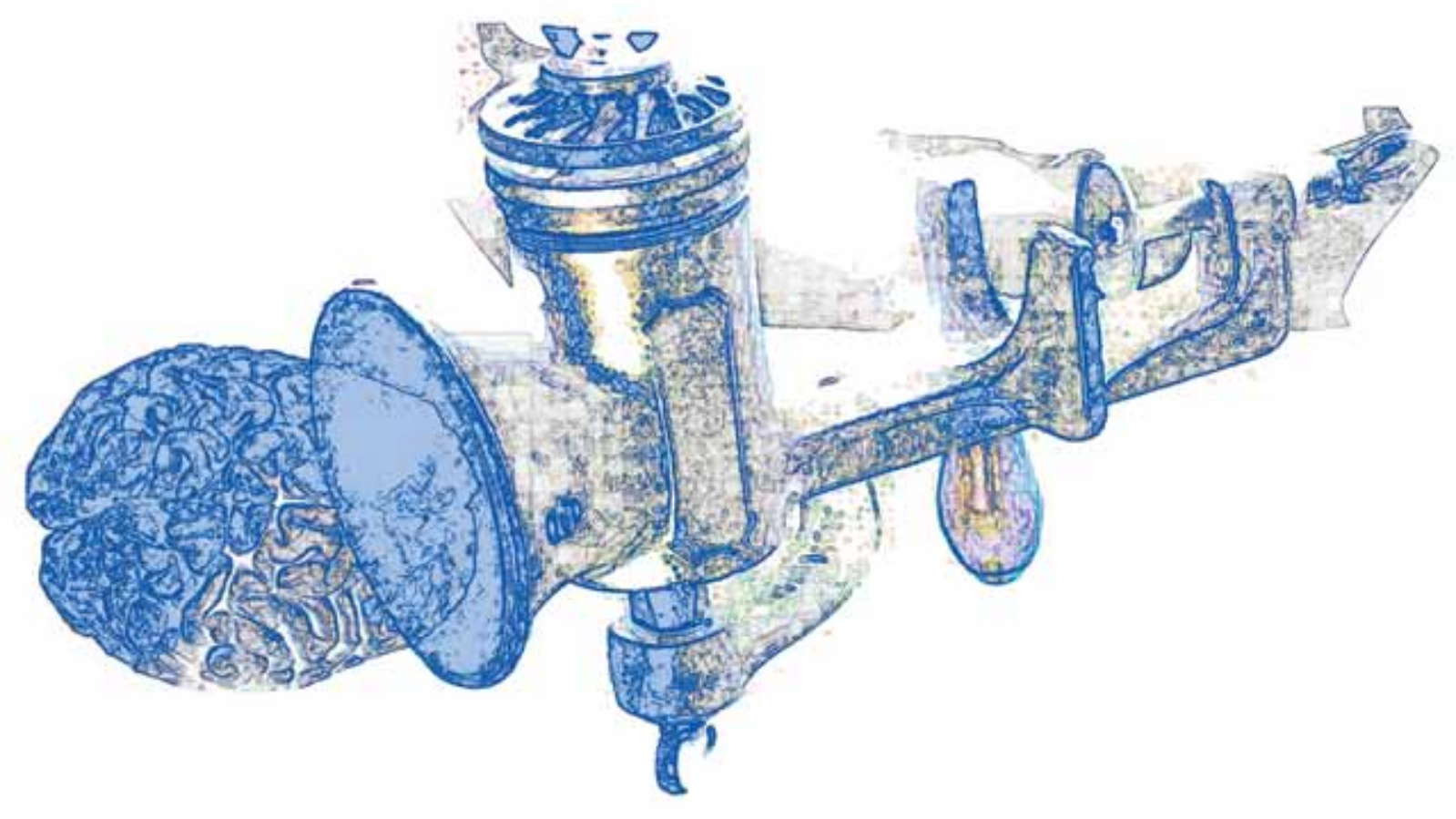


0 mundo vive hoje uma revolução digital. Internet e telefones celulares já são a primeira forma de lazer para pessoas com idade inferior a 55 anos. Estão à frente de cinemas, jornais e TVs, de acordo com a UIT (União Internacional de Telecomunicações), agência das $\mathrm{N}$ ações Unidas. 0 telefone fixo demorou 125 anos para atingir 0 primeiro bilhão de usuários. A expectativa é de que, em 2008, mais de 3 bilhões de pessoas possuam um aparelho celular. Atualmente, são cerca de 300 milhões de usuários de Internet banda larga no mundo.

\section{As mudanças que os jornais estão}

\section{experimentando não são mero fruto das}

\section{inovações tecnol ógicas: decorrem di retamente}

da mudança (ou mesmo da falência) de um

modo de pensar, de uma maneira de ver o

\section{mundo, de uma sociedade que aprofunda}

\section{cada vez mais sua espetacularização.} istribuição para existir.

grande vantagem: sites da Internet não requerem rotativas, bobinas de papel, eletricidade e complexas redes de

Com o avanço das tecnologias móveis, celulares e palm-tops se transformaram em centros de entretenimento pessoal em que a notícia pode ser facilmente adquirida em qualquer lugar de forma fácil, rápida e gratuita. Ou seja, em virtude das novas tecnologias, cada vez mais as pessoas consideram 0 acesso à informação um bem gratuito e estão muito menos dispostas a pagar, mesmo que um baixo valor, para ter acesso a notícias que já foram vistas no dia anterior nas páginas da Internet.

Com a proliferação das mídias cresceram também os meios em que anúncios e propaganda podem ser feitos. Com isso, as verbas publicitárias ficaram muito mais dispersas entre os diferentes meios de comunicação. Todas as organizações de mídia estão sentindo a dispersão da verba publicitária na pele. N esse cenário, as empresas que produzem jornais estão pensando e praticando o que era impensável há muito

Com isso, a tecnologia, que, por um lado, reduziu drasticamente os custos de produção dos jornais por outro está destruindo seu modelo de negócio. Com a Internet, os grupos (anunciantes específicos, compradores, pessoas ávidas por notícias, empresas) que sempre tiveram os jornais como espaço obrigatório de interação podem potencialmente se relacionar diretamente de forma mais eficiente e rápida. Os classificados não têm mais tanto apelo em um mundo em que qualquer produto está a um clique de distância.

O sucesso de sites como eBay e Mercado Livre demonstram esse fato. As ferramentas de busca possibilitam a comparação de preços em inúmeros canais de venda ao mesmo tempo. A procura por uma nova casa é muito mais ágil em sites específicos, e o mesmo acontece com carros e empregos. Notícias e informações de todos os tipos, de qualquer lugar do mundo, podem ser adquiridas de forma gratuita nas mais diversas páginas da Internet com uma pouco tempo, embora ainda um pouco perdidos.

R eações e alternativas. Tipicamente, os jornais tentam reagir aos desafios da era digital seguindo o script das organizações em declínio e adotam medidas paliativas. 0 primeiro passo é sempre tentar reduzir ao máximo os custos. Com isso, jornalistas são demitidos. Os que ficam têm de trabalhar mais intensamente e em piores condições, pois recursos de todos os tipos e de todas as formas são cortados. Menos jornalistas e recursos significam que os jornais ficam cada vez mais dependentes das agências de notícias.

O utra solução pal iativa tem sido a alteração de formato e projeto gráfico dos jornais, além do aumento da pasteurização do conteúdo com as mesmas notícias nos diferentes veículos. Há a redução dos espaços para articulistas e análise aprofundada de notícias e 0 aumento das imagens e de notícias relacionadas a celebridades. Afinal, é o que se espera na Sociedade do Espetáculo. 
Outras medidas parecem estrategicamente mais coerentes. Muitos jornais migraram para a Internet e passaram também a oferecer conteúdo on-line em portais que vão além das notícias, oferecendo blogs, redes de relacionamento amoroso e envio de notícias para celulares, porém diversos estudos mostram que a receita gerada nos sites dos jornais não cobre os custos de uma migração definitiva.

O utra prática comum é o desenvolvimento de sites específicos para segmentos de classificados. 0 The Guardian, na Inglaterra, tem um site sobre carros que atingiu muito sucesso. Com isso, as grandes empresas jornalísticas estão caminhando no sentido de alterar seu foco estratégico. Deixam de ser empresas que produzem somente jornais para se transformar em provedores de notícias pelos mais diversos meios, como sites de Internet, jornais impressos, jornais regionais, rádios, TVs etc.

Há também inovações acontecendo a fim de gerar a maior participação dos consumidores dos jornais em seu conteúdo. Tradicionalmente editores tomam decisões a respeito do que énotícia, no entanto al gumas organizações estão revertendo essa tendência. Um jornal chileno, por exemplo, leva às últimas conseqüências a participação dos leitores: a ordem de importância das notícias no jornal é estabelecida por aquilo que foi mais lido no site do jornal na Internet. A estratégia tem surtido efeito e o jornal aumentou suas vendas.

Outra iniciativa que parece promissora é a criação dos jornais gratuitos. 0 M etro, no Reino Unido, é hoje o maior jornal gratuito do mundo, com uma circulação diária, durante a semana, de pouco mais de 1 milhão de cópias, transformando-se em um fenômeno de circulação desde que foi criado em 1999. Trata-se de um tablóide, com notícias curtas e diretas, distribuído gratuitamente nos meios de transporte público. O u seja, éum jornal ideal para ser lido dentro do ônibus ou do trem no trajeto de ida e volta do trabalho.

No Brasil, a maioria dos jornais é feita para pessoas de classe social alta, bem instruídas e relativamente politizadas. Jornais populares são raros. Não é à toa que recente pesquisa, patrocinada pela Associação $\mathrm{N}$ acional de Jornais, mostra que o número de leitores de jornais aumenta à medida que também aumentam a instrução e a classe social das pessoas. Isso representa uma grande oportunidade de mercado para as empresas de jornal se elas decidirem olhar para 0 andar de baixo da pirâmide social.

A revista The Economist, em recente capa, chama a atenção para a decadência dos jornais e argumenta que esse não é um problema, pois a Internet possibilita a difusão de informações. Por isso, o papel que os jornais desempenham na consolidação e constante renovação da democracia, nas investigações e controle dos agentes públicos e privados, terá com a Internet um melhor desempenho. Porém, a Internet também gera um bombardeio e a pluralização das fontes de informações. Torna-se então muito mais difícil saber o que é relevante ou até mesmo ter uma noção geral do que acontece.

Perspectivas. 0 futuro é incerto por definição. Mas é possível perceber que os jornais terão de se reinventar para sobreviver. Alguns já caminham nesse sentido e mostram que 0 jornal que as pessoas podem querer comprar fala mais de entretenimento, da vida das celebridades, de problemas emocionais das pessoas, da novela e dos seriados de televisão. As notícias são curtas, breves e escritas da forma mais didática possível. As pautas tenderão a refletir mais o que os leitores querem ler, e não aquilo que os editores consideram importante.

Nada mais adequado para uma sociedade que cultua a imagem e a aparência, que cada vez mais se mostra menos interessada por assuntos públicos e se enclausura pelo privado. As mudanças que os jornais estão experimentando não são mero fruto das inovações tecnológicas, mas a conseqüência direta da mudança, ou mesmo da falência, de um modo de pensar, de uma maneira de ver o mundo, de uma sociedade que aprofunda cada vez mais sua espetacularização. Talvez, a sua decadência, ao menos na forma tradicional, seja somente mais um indício da decadência de uma era.

\section{Rafad Alcadipani}

Pesquisador e doutorando na Manchester Business School, Inglaterra

Prof. do Departamento de Administração Geral e Recursos Humanos da FGV-EAESP

E-mail: Ralcadipani@hotmail.com 